\title{
Magnetism-Enhanced Monolith-Based In-Tube Solid Phase Microextraction
}

\author{
Meng Mei ${ }^{1}$, Xiaojia Huang ${ }^{* 1}$, Qing Luo ${ }^{2}$, Dongxin Yuan ${ }^{1}$ \\ 1. State Key Laboratory of Marine Environmental Science, Key Laboratory of the \\ Ministry of Education for Coastal and Wetland Ecosystem, College of the \\ Environment and Ecology, Xiamen University. \\ 2. Department of Materials Science and Engineering, College of Materials, Xiamen \\ University, Xiamen 361005, China
}

*Corresponding author. Tel: 086-0592-2189278; Fax: 086-0592-2183137

E-mail: hxj@xmu.edu.cn

Corresponding Address: P. O. Box 1009, Xiamen University, Xiamen 361005, China 


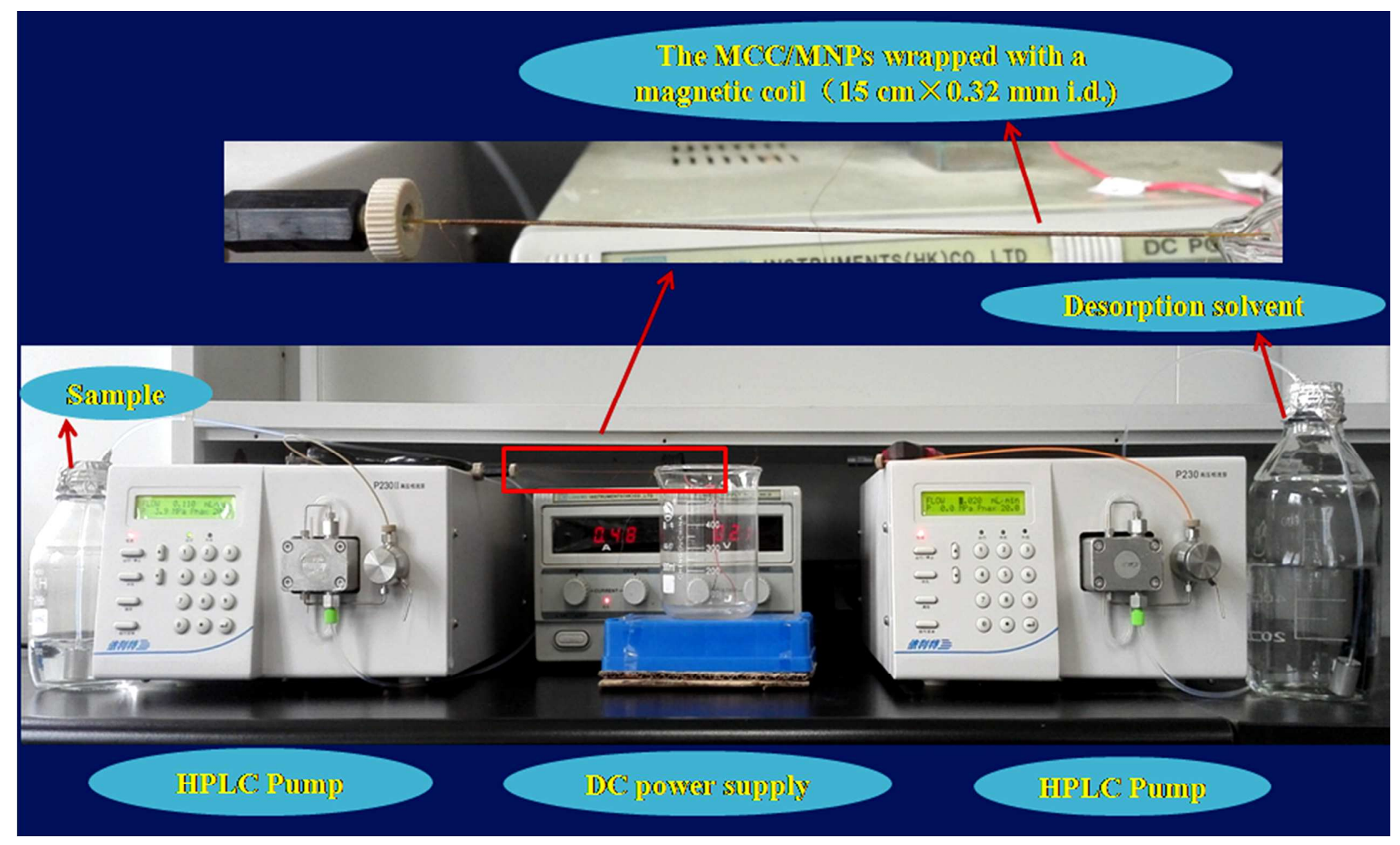

Figure S-1. The experimental set-up of ME-MB/IT-SPME 

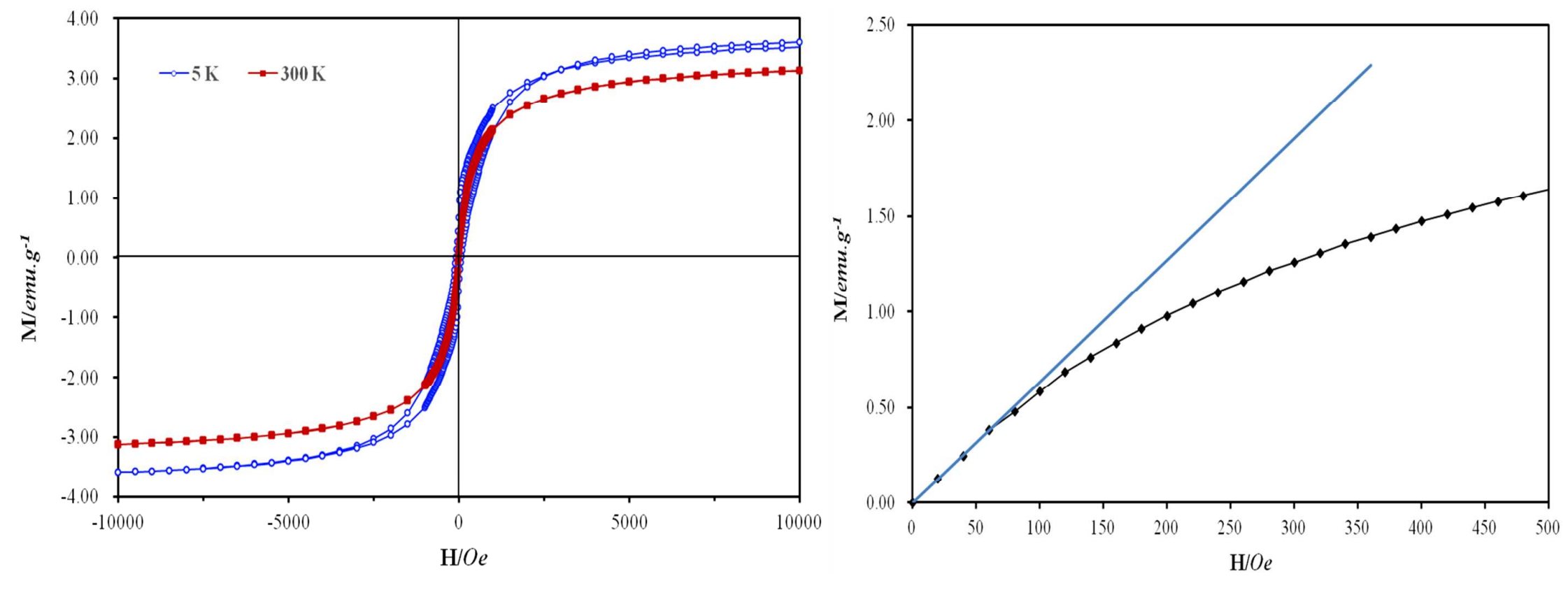

b

Figure S-2. a) Magnetization versus applied magnetic field of the MCC/MNPs at room temperature $300 \mathrm{~K}$ (superparamagnetic behavior, red) and a $\mathrm{T}=5 \mathrm{~K}$ (ferromagnetic behavior, blue) with a coercive field of ca. 100 Oe.

b) Magnetization versus applied magnetic field of the MCC/MNPs at a temperature of $300 \mathrm{~K}$ (dots-line, black), the blue line shows the sharp linear increase in the region of approximately 0-60 Oe. 


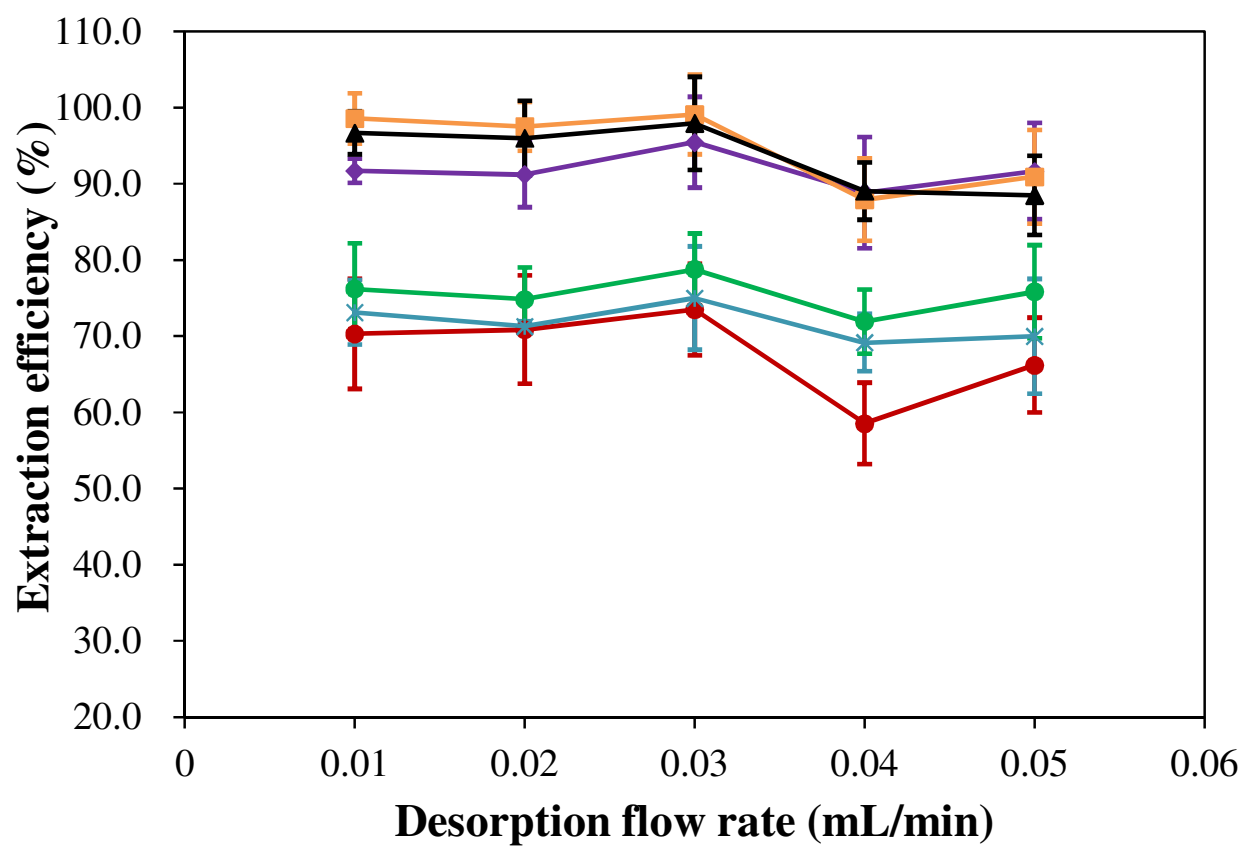

Figure S-3. The effect of desorption flow rate on extraction efficiency

Conditions: the intensity of magnetic filed in adsorption and desorption steps were 30 (Gs) and -30 (Gs), respectively; the volume of sample and desorption solvent (methanol) were $3.0 \mathrm{~mL}$ and $0.1 \mathrm{~mL}$, respectively; the adsorption flow rates was 0.12 $\mathrm{mL} / \mathrm{min}$. The spiked concentration for each compound was $0.1 \mu \mathrm{g} / \mathrm{L}$.

Symbols: $\diamond \mathrm{BPA} ; \quad$ EE2; $\triangle \mathrm{ES} ; \diamond \mathrm{DES} ; * \mathrm{DS} ; \bullet \mathrm{NP}$ 


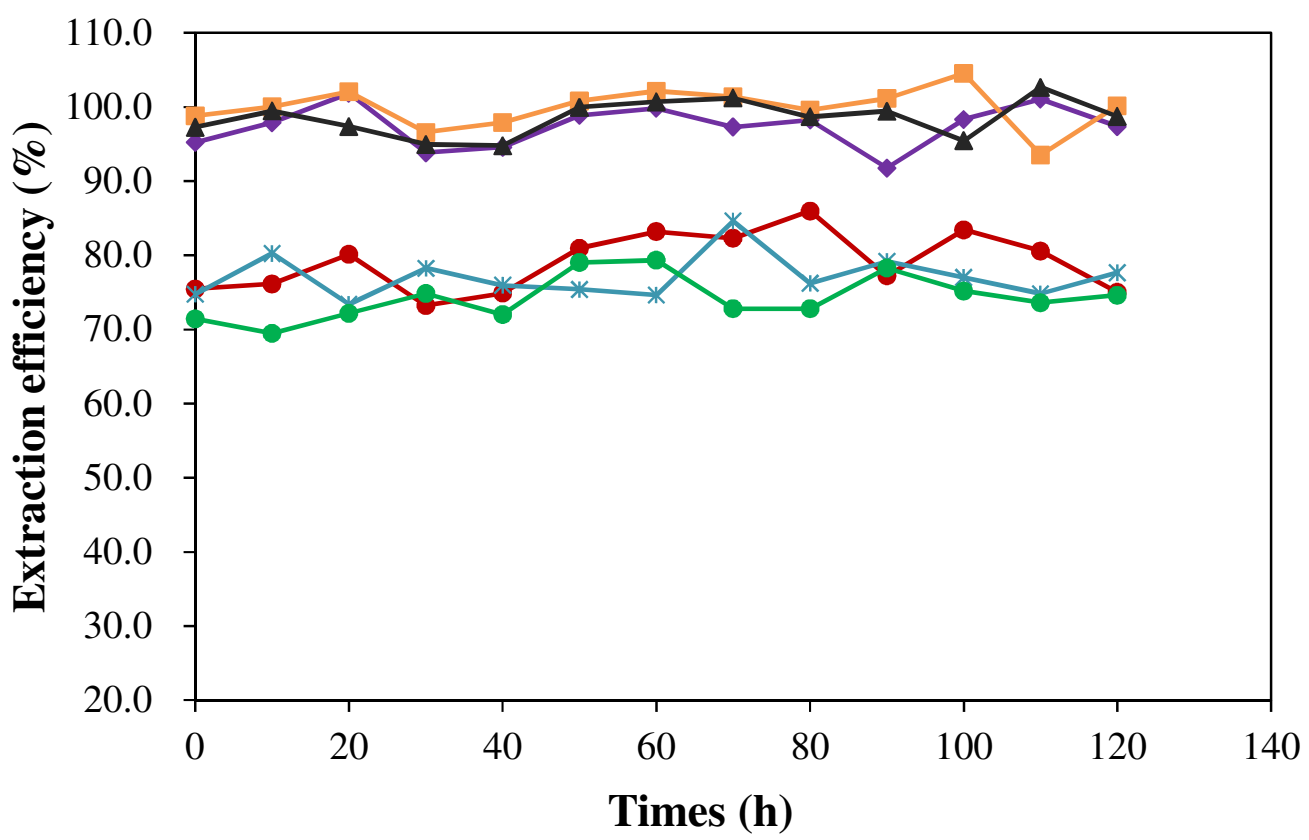

Figure S-4. The life-span investigation of MCC/MNPs

Conditions: the desorption rate was $0.03 \mathrm{~mL} / \mathrm{min}$. The other conditions and symbols were the same as in Fig.S2.

\section{The relationship of intensity of magnetic field with current}

The intensity of magnetic field (B) is calculated as follows:

$$
\mathrm{B}=\mu_{0} \mathrm{nI}
$$

$\mu_{0}$ : permeability of vacuum, the value is $4 \pi \times 10^{-7} \mathrm{~N} \cdot \mathrm{A}^{-2}$;

$\mathrm{n}$ : coil number in per unit length, $\mathrm{m}^{-1}$, the value is $5000 \mathrm{~m}^{-1}$ at present study;

I: current, A;

The unit of B is Tesla (T), 1T $=1 \mathrm{~N} \cdot \mathrm{A}^{-1} \mathrm{~m}^{-1}=10^{4} \mathrm{Gs}$

For example, if we want to apply a magnetic field with the intensity of $30 \mathrm{Gs}$, the needed current is calculated as follows:

$$
\begin{aligned}
& 30 \times 10^{-4} \mathrm{~N} \cdot \mathrm{A}^{-1} \mathrm{~m}^{-1}=4 \pi \times 10^{-7} \mathrm{~N} \cdot \mathrm{A}^{-2} \times 5000 \mathrm{~m}^{-1} \times \mathrm{I} \\
& \mathrm{I}=0.48 \mathrm{~A}
\end{aligned}
$$

\section{Reference:}

[1] Edit by J.J. Mao, M. Gu, Phycics for University (Volume One), Higher education press, Beijing, 2006.1.

\section{Chemicals}

$\mathrm{FeCl}_{3} \cdot 6 \mathrm{H}_{2} \mathrm{O}(99 \%), \mathrm{FeCl}_{2} \cdot 4 \mathrm{H}_{2} \mathrm{O}(98 \%)$, tetraethylorthosilicate (TEOS) (98\%) and 
PEG4000 was supplied from Xilong Chemical (Guangzhou, China);HPLC-grade acetonitrile (ACN) and methanol were purchased from Tedia Company (Fairfield, USA); Water used throughout the study was purified using a Milli-Q water purification system (Millipore, USA). Water samples were collected from Xiamen city and filtrated through $0.45 \mu \mathrm{m}$ membranes. All samples were stored at $-4{ }^{\circ} \mathrm{C}$ before use. Individual stock solutions of estrogens were prepared at a concentration of $10.0 \mathrm{mg} / \mathrm{L}$ by dissolving methanol and renewed monthly. The standard mixtures of estrogens were prepared by dissolving $2.00 \mathrm{mg}$ of each compound in methanol in 100 $\mathrm{mL}$ volumetric flask. The stock solutions were stored at $4{ }^{\circ} \mathrm{C}$ and diluted with ultrapure water to give the required concentration.

\section{Instruments}

The morphologies of MCC/MNPs were investigated using transmission electron microscopy (TEM) (JEOL 2011 microscope, Japan) and scanning electron microscopy (SEM) (Philips, Eindhoven, the Netherlands). Magnetic properties of the MCC/MNPs were characterized by a PPMS-9 vibrating sample magnetometer (QUANTOM, USA); DC power supply TPR-6405D was supplied by Long Wei instruments (HK) Co., Ltd (Guangzhou, China). The high pressure pumps P230 II were purchased from Dalian Elite Analytical Instruments Co., Ltd (Dalian, China).

\section{Synthesis of modified magnetic nanoparticles}

$\mathrm{FeCl}_{3} \cdot 6 \mathrm{H}_{2} \mathrm{O}(5.8 \mathrm{~g})$ and $\mathrm{FeCl}_{2} \cdot 4 \mathrm{H}_{2} \mathrm{O}(2.2 \mathrm{~g})$ were dissolved in $200 \mathrm{~mL}$ ultrapure water with a mechanical stirring at $80{ }^{\circ} \mathrm{C}$, then $10 \mathrm{~mL}$ ethanediamine was added dropwise into above solution under nitrogen gas protection and vigorously mechanical stirring for $2 \mathrm{~h}$. After the reaction, the obtained $\mathrm{Fe}_{3} \mathrm{O}_{4}$ particles were separated from the reaction medium by a magnetic field. The $\mathrm{Fe}_{3} \mathrm{O}_{4}$ particles were washed with water/methanol repeatedly with the aid of a magnet, and then dried under vacuum at $60{ }^{\circ} \mathrm{C}$ to get $\mathrm{Fe}_{3} \mathrm{O}_{4}$ nanoparticles. The prepared $\mathrm{Fe}_{3} \mathrm{O}_{4}$ particles $(1.0 \mathrm{~g})$ were dispersed in $100 \mathrm{~mL}$ 2-propanol by sonication for more than $15 \mathrm{~min}$, following by the addition of $60 \mathrm{~mL}$ ammonia $(25 \%, \mathrm{w} / \mathrm{V})$ and $10 \mathrm{~mL}$ TEOS sequentially. The mixture was reacted for $12 \mathrm{~h}$ at room temperature under continuous stirring. The resultant product was collected by an external magnetic field, thoroughly rinsing with water/methanol repeatedly. The product was dried to powder in vacuum to get $\mathrm{Fe}_{3} \mathrm{O}_{4} @ \mathrm{SiO}_{2}$. After that, 
$1.0 \mathrm{~g}$ of $\mathrm{Fe}_{3} \mathrm{O}_{4} @ \mathrm{SiO}_{2}$ was reacted with $1.0 \mathrm{~mL}$ of $\gamma$-MAPS using triethylamine as a catalyst in $10 \mathrm{~mL}$ methanol under the nitrogen atmosphere at $60{ }^{\circ} \mathrm{C}$ for $12 \mathrm{~h}$. The particles were washed several times with methanol and dried under vacuum for $6.0 \mathrm{~h}$ at $50{ }^{\circ} \mathrm{C}$ to get $\mathrm{Fe}_{3} \mathrm{O}_{4} @ \mathrm{SiO}_{2} @ \gamma-\mathrm{MAPS}$. 
Table S-1. Confirmatory study of determination of estrogens in wastewater samples with developed method and HLB-based SPE-HPLC/DAD

\begin{tabular}{|c|c|c|c|c|c|c|c|}
\hline \multirow{2}{*}{ Samples } & \multirow{2}{*}{ Method } & \multicolumn{6}{|c|}{ Concentration $(\mu \mathrm{g} / \mathrm{L}) /(\% \mathrm{RSD}, \mathrm{n}=3)$} \\
\hline & & BPA & EE2 & ES & DS & DES & NP \\
\hline \multirow[t]{2}{*}{ Hospital wastewater } & ME-MB/IT-SPME-HPLC/DAD ${ }^{a}$ & $19.9(4.6)$ & $7.7(4.0)$ & $5.6(6.5)$ & $17.8(3.1)$ & $6.5(4.7)$ & ND \\
\hline & SPE-HPLC/DAD ${ }^{b}$ & $20.6(2.3)$ & $7.3(4.2)$ & $6.1(6.3)$ & $18.6(5.0)$ & $6.6(2.0)$ & ND \\
\hline \multirow{2}{*}{$\begin{array}{l}\text { Wastewater treatment plant } \\
\text { (Inlet) }\end{array}$} & ME-MB/IT-SPME-HPLC/DAD & $44.7(2.6)$ & ND & $3.4(5.3)$ & $12.2(5.6)$ & ND & $4.8(9.7)$ \\
\hline & SPE-HPLC/DAD & $46.0(4.0)$ & ND & $3.3(7.2)$ & $12.4(6.2)$ & ND & $4.7(5.5)$ \\
\hline \multirow{2}{*}{$\begin{array}{l}\text { Wastewater treatment plant } \\
\text { (Outlet) }\end{array}$} & ME-MB/IT-SPME-HPLC/DAD & $15.0(8.1)$ & ND & ND & $4.7(6.5)$ & ND & $2.3(6.7)$ \\
\hline & SPE-HPLC/DAD & $13.9(6.6)$ & ND & ND & $5.0(3.3)$ & ND & $2.6(1.2)$ \\
\hline
\end{tabular}

ND: not detected.

a: The conditions can be seen in the part of "The Procedure of ME-MB/IT-SPME" in the manuscript.

b: The HLB-based SPE conditions can be found in the reference (Environ. Sci. Technol. 2012, 46, 6750-6758). Briefly, HLB cartridge (0.5 g) was cleaned and conditioned with $4 \times 2.5 \mathrm{~mL}$ of $\mathrm{MeOH}$, followed by $4 \times 2.5 \mathrm{~mL}$ of reagent water. A 50 -mL aliquot of filtered wastewater was then loaded onto HLB cartridge at a flow rate of 1-2 drops per second. The cartridge was then washed with $3 \times 2.5 \mathrm{~mL}$ of $20 \% \mathrm{MeOH}$ in ultrapure water, after which it was allowed to dry under vacuum (10 in. of $\mathrm{Hg}$ ) for $45 \mathrm{~min}$. Finally, the cartridges were eluted with $7.5 \mathrm{~mL}$ of $\mathrm{MeOH}$ and the eluate was collected. The eluate was then reduced in volume to approximately 200-300 $\mu \mathrm{L}$ under a gentle stream of nitrogen in a water bath at $40{ }^{\circ} \mathrm{C}$ and reconstituted to $1 \mathrm{~mL}$ with $\mathrm{MeOH}$. A 20- $\mu \mathrm{L}$ eluate was used for HPLC analysis. 